\title{
THE
}

$5-1-2015$

\section{Icebergs and Sea Ice Detected with Inverted Echo Sounders}

M. Andres

A. Silvano

F. Straneo

D. R. Watts

University of Rhode Island, randywatts@uri.edu

Follow this and additional works at: https://digitalcommons.uri.edu/gsofacpubs

Terms of Use

All rights reserved under copyright.

\section{Citation/Publisher Attribution}

M. Andres, A. Silvano, F. Straneo, and D. R. Watts. (2015). "Icebergs and sea ice detected with inverted echo sounders." Journal of Atmospheric and Oceanic Technology, 32, 1042-1057.

Available at: http://dx.doi.org/10.1175/JTECH-D-14-00161.1

This Article is brought to you for free and open access by the Graduate School of Oceanography at DigitalCommons@URI. It has been accepted for inclusion in Graduate School of Oceanography Faculty Publications by an authorized administrator of DigitalCommons@URI. For more information, please contact digitalcommons-group@uri.edu. 


\title{
Icebergs and Sea Ice Detected with Inverted Echo Sounders
}

\author{
M. ANDRES \\ Physical Oceanography Department, Woods Hole Oceanographic Institution, Woods Hole, Massachusetts
}

A. Silvano

Physical Oceanography Department, Woods Hole Oceanographic Institution, Woods Hole, Massachusetts, and University of Turin, Turin, Italy

F. STRANEO

Physical Oceanography Department, Woods Hole Oceanographic Institution, Woods Hole, Massachusetts

\author{
D. R. WATTS
}

Graduate School of Oceanography, University of Rhode Island, Narragansett, Rhode Island

(Manuscript received 18 August 2014, in final form 3 March 2015)

\begin{abstract}
A 1-yr experiment using a pressure-sensor-equipped inverted echo sounder (PIES) was conducted in Sermilik Fjord in southeastern Greenland $\left(66^{\circ} \mathrm{N}, 38^{\circ} \mathrm{E}\right)$ from August 2011 to September 2012. Based on these high-latitude data, the interpretation of PIESs' acoustic travel-time records from regions that are periodically ice covered were refined. In addition, new methods using PIESs for detecting icebergs and sea ice and for estimating iceberg drafts and drift speeds were developed and tested. During winter months, the PIES in Sermilik Fjord logged about 300 iceberg detections and recorded a 2-week period in early March of land-fast ice cover over the instrument site, consistent with satellite synthetic aperture radar (SAR) imagery. The deepest icebergs in the fjord were found to have keel depths greater than approximately $350 \mathrm{~m}$. Average and maximum iceberg speeds were approximately 0.2 and $0.5 \mathrm{~m} \mathrm{~s}^{-1}$, respectively. The maximum tidal range at the site was $\pm 1.8 \mathrm{~m}$ and during neap tides the range was $\pm 0.3 \mathrm{~m}$, as shown by the PIES's pressure record.
\end{abstract}

\section{Introduction}

The Greenland Ice Sheet sequesters about 2.9 million $\mathrm{km}^{3}$ of water (Bamber et al. 2001) and serves as a significant freshwater source to the ocean. Recent estimates suggest that ice-sheet loss from Greenland is contributing about $0.7 \mathrm{~mm} \mathrm{yr}^{-1}$ to global mean sea level rise (Rignot et al. 2011). Freshwater enters the oceans from the ice sheet via surface meltwater runoff forced by atmospheric heating and via basal melting driven at the ice sheet's marine-terminating glaciers (Straneo et al. 2013 and references therein).

In addition to this meltwater contribution, a significant fraction of the freshwater flux from Greenland

Corresponding author address: Magdalena Andres, Physical Oceanography Department, Woods Hole Oceanographic Institution, MS 21, 266 Woods Hole Road, Woods Hole, MA 02543. E-mail: mandres@whoi.edu enters the ocean as icebergs that have calved from marine-terminating glaciers. These icebergs may travel great distances from their source region with icebergs routinely spotted off Newfoundland, Canada, and in some cases as far south as $40^{\circ} \mathrm{N}$ before they melt completely [see Fig. 2 in Bigg et al. (1996) and references therein]. Though the melting of an iceberg along its trajectory does not continually add to sea level (that contribution occurs as soon as an ice tongue or iceberg is floating freely), the progressive melting does lead to a diffuse freshwater flux into the ocean at high latitudes.

Modeling studies suggest that the freshwater flux at high latitudes strongly influences thermohaline circulation and deep-water formation. Hosing experiments with climate models, where freshwater is added as a cap over the North Atlantic between $50^{\circ}$ and $70^{\circ} \mathrm{N}$, have shown that the addition of a $0.1-\mathrm{Sv}\left(1 \mathrm{~Sv} \equiv 10^{6} \mathrm{~m}^{3} \mathrm{~s}^{-1}\right)$ freshwater anomaly slows the thermohaline circulation 
by $\sim 30 \%$ and a $1-\mathrm{Sv}$ perturbation essentially shuts it down altogether (Stouffer et al. 2006). The details of how freshwater enters the system are critical for determining the oceanic response, since deep convection occurs in localized regions (e.g., Pickart et al. 2003). While a freshwater cap, diffuse sources (e.g., melting of drifting icebergs), or point sources (e.g., runoff and melting at the heads of fjords) likely each have different impacts on the thermohaline circulation, these potential effects are presently not well constrained. Incorporating accurate freshwater fluxes into ocean general circulation models (OGCMs) or properly parameterizing the relevant processes for inclusion in climate models requires detailed knowledge of the frequency of iceberg occurrences, and their trajectories, drafts, and melting rates.

Evidence suggests that the rate of freshwater discharge from Greenland, including that carried by icebergs exported from fjords in northwestern and southeastern Greenland, accelerated in the early 2000 s (e.g., Enderlin et al. 2014). To put the recent acceleration into context, deposits of ice-rafted debris, which has accumulated on the fjord bed (Boldt et al. 2013 and references therein), have been used to infer the history of calving and iceberg discharge rate (e.g., Andresen et al. 2012). In these studies, it is often assumed that changes in sediment deposition rate primarily reflect changes in iceberg discharge rate rather than variations in iceberg melt rate or changes in the icebergs' residence times in the fjord. Since little is known about the temporal and spatial variability of melt rates and residence times, the histories of iceberg discharge reconstructed from sediment studies are not yet very well constrained. Although iceberg residence times can be estimated from Lagrangian trackers mounted on individual icebergs (Sutherland et al. 2014) and basal iceberg melt rates have been estimated using repeat high-resolution stereo images from satellites (Enderlin and Hamilton 2014), these studies have examined relatively few icebergs.

In addition to icebergs' effects on ocean and fjord circulation and their impact on sedimentation rates in fjords, icebergs also present tremendous risk for oceanographic and commercial equipment. They are hazards to ships and natural resource exploration, and extraction equipment and iceberg keels can destroy even deep moorings (Jackson 2014). The Canadian Ice Service and U.S. Coast Guard International Ice Patrol routinely track iceberg positions and use models to predict their drift and deterioration (e.g., Kubat et al. 2005, 2007).

Despite icebergs' potential role in shaping ocean circulation via their contribution to the ocean's freshwater flux and despite the risks they pose to ships and equipment, studies of icebergs based on in situ measurements have been quite limited to date and some operational iceberg forecasts rely on empirical relationships from just a few icebergs (e.g., Barker et al. 2004).

Here we present a methodology for the use of an existing technology in a new application that enables in situ, ocean-based observations of icebergs and sea ice in fjords and high-latitude oceans. The instruments are inverted echo sounders (IESs) further equipped with a pressure sensor (PIESs). PIESs traditionally have been used for process studies in (ice free) strong current and eddy systems to infer the ocean's density structure and horizontal velocities. The primary purpose of a recent PIES deployment in Sermilik Fjord, Greenland, was to test its use in an icy environment as a way to measure the time-varying heat content in high-latitude seas, shelves, and fjords (Andres et al. 2014). However, the presence of sea ice and ubiquitous icebergs had an interesting (and somewhat unexpected) effect on the PIES's acoustic travel-time record: while it was anticipated that the ice might lead to noise, which would have to be carefully filtered to obtain an unbiased record of the fjord's time-varying heat content, some of this "noise"- due to detections of ice-water interfacescan be interpreted to gain information about the ice in the fjord.

Section 2 describes the principle of operation of an IES and its conventional applications. Section 3 explains the new methodology to use these moorings, which are deployed on the seafloor out of reach of most iceberg keels, to (i) detect the presence of icebergs and land-fast sea ice; (ii) constrain iceberg and sea ice draft estimates; and (iii) estimate iceberg speed. Section 4 demonstrates an application of the methods developed here with measurements from a field program carried out in Sermilik Fjord in southeastern Greenland (Fig. 1), which abuts Helheim Glacier, one of Greenland's most prolific iceberg producers. Concluding remarks, including a discussion of the strengths and limitations of the new methodology developed here, are presented in section 5.

\section{Inverted echo sounders}

An IES sits on the ocean bottom in a rigid anchor stand or attached to a very short $(<1.5 \mathrm{~m})$ mooring line (Fig. 2). It is designed to operate in water depths between 500 and $6700 \mathrm{~m}$ for deployments lasting up to 5 years. The IES emits $12-\mathrm{kHz}$ pings and receives and records each ping's first echo, excluding those echoes that arrive from nearby reflectors-such as bottom topography, overlying mooring floats, or biological material-with a "lockout time." A total of 24 pings are emitted each hour. These have a 6-ms duration and spacing alternating between 16 and $18 \mathrm{~s}$. In the 


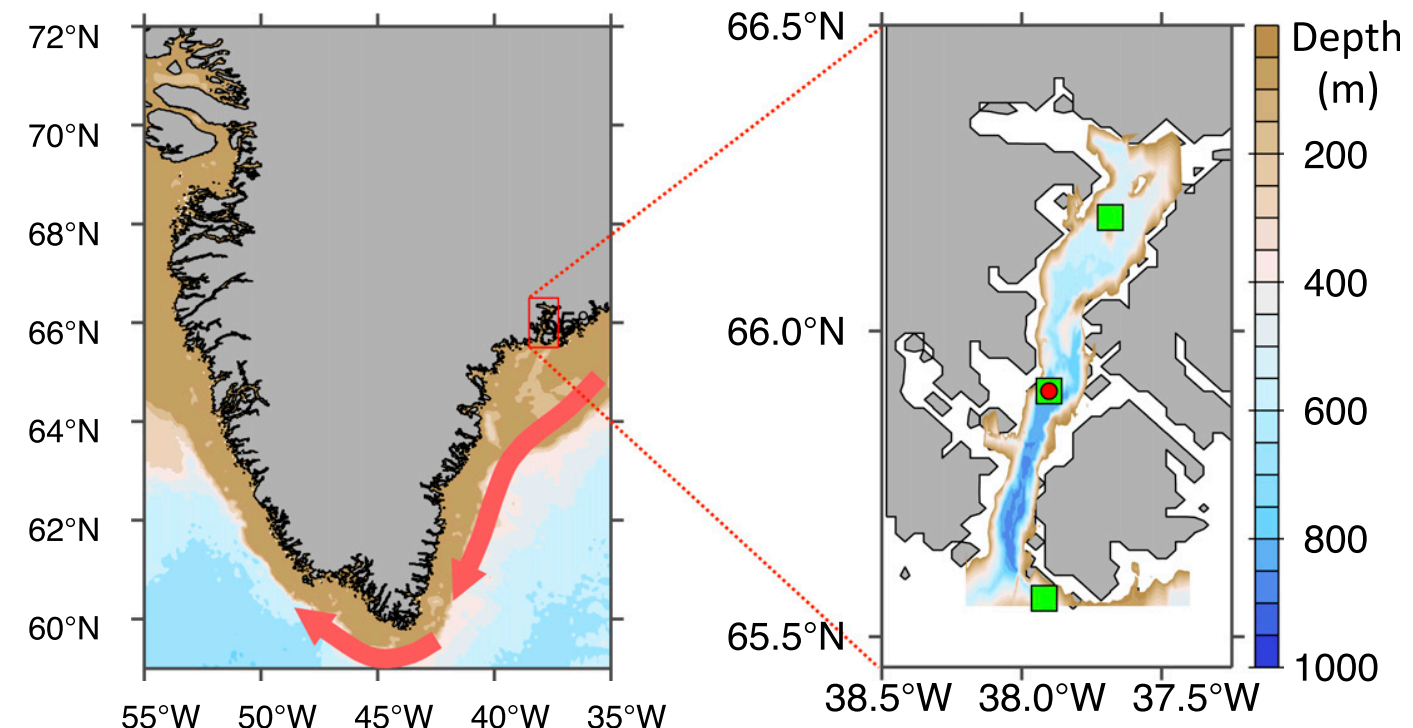

FIG. 1. (left) Map of southern Greenland and (right) close up of Sermilik Fjord. Red arrows in (left) indicate the East Greenland Current system (Sutherland and Pickart 2008; Harden et al. 2014), which advects icebergs that exit the fjord [see Fig. 1 in Bigg et al. (1996) for modeled iceberg trajectories]. The PIES at site G1 in Sermilik Fjord is identified (red circle in right panel) as are locations of PIESs in an ongoing follow-on field program (green squares) deployed in August 2013 (recovery planned for August 2015).

application described here, the instrument is programmed to distribute the 24 pings within the hour, with six bursts of 4 pings emitted in 10-min intervals. After each four-ping burst, the instrument records only the round-trip acoustic travel time of the first four echoes that fall above a minimum intensity threshold. Strong reflectors (like the air-sea and ice-sea interfaces) are detected and recorded by the IES, whereas weak reflections (like those from the pycnocline) are not.

An IES can be equipped with a pressure sensor (PIES), in which case hourly pressure $P_{b}$ and temperature $T_{b}$ near the seafloor are also recorded. Details of the instrument's technical specifications are available online (http://www.po.gso.uri.edu/dynamics/ies/specs table.pdf). Unlike tall moorings, which typically have large anchors and long wires, IESs and PIESs can be deployed and recovered from small boats, which is often advantageous for fieldwork in fjords. (See http://www. po.gso.uri.edu/dynamics/ies/movie.html for videos of a PIES deployment and recovery.)

\section{a. Acoustic travel time}

The round-trip acoustic travel time $\tau$ between an IES and a reflector depends on the intervening pathlength $L$
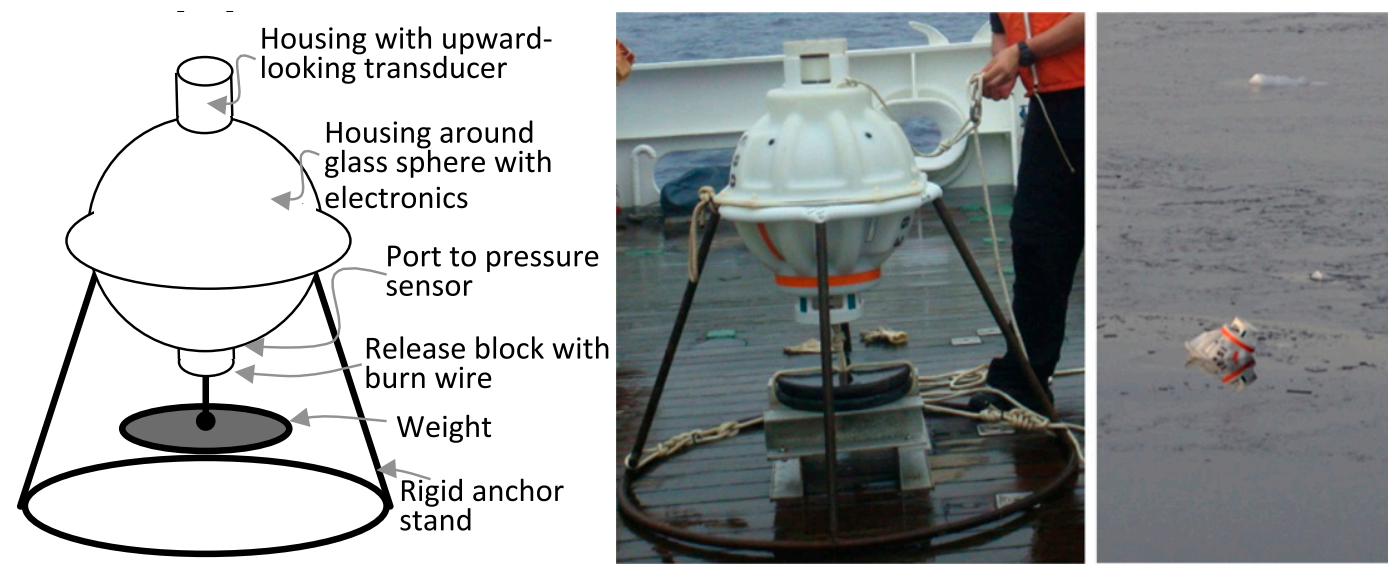

FIG. 2. (left) PIES schematic, (middle) PIES on deck, ready for deployment, and (right) awaiting retrieval from the sea surface after a mission. The rigid anchor stand and weight are not retrieved on recovery. 
and the average speed of sound in seawater along the path $\bar{c}$,

$$
\tau=2 L / \bar{c}
$$

Here $\bar{c}$ is a function of the seawater's temperature, salinity, and pressure along $L$. In conventional IES and PIES applications (see Donohue et al. 2010 for a review), reflections from the overlying sea surface are used to deduce the time-varying $\bar{c}$ (either by assuming $L$ is constant, or by correcting for small changes in $L-$ due to, for example, the barotropic tide-with $P_{b}$ measurements). Then, $\bar{c}$ is used with local historical hydrography to infer a water column's time-varying thermocline depth, dynamic height, heat content, or vertical temperature and salinity profiles (Rossby 1969; Meinen and Watts 2000). Based on temperature and salinity profiles measured in Sermilik Fjord, the expected range in $\tau$ in the fjord that arises from variations in $\bar{c}$ is about a $5-\mathrm{ms}$ round trip (F. Straneo et al. 2015, unpublished manuscript). For comparison, if $\bar{c}$ were constant, then a 5 -ms range in $\tau$ would represent a $3.7-\mathrm{m}$ change in $L$. This uncertainty in $L$ is relevant only for those reflections that are not from the sea surface; for reflections from the sea surface, $L$ is well constrained by the pressure record, which has an absolute accuracy equivalent to approximately $40 \mathrm{~cm}$ of seawater (i.e., absolute accuracy is $0.01 \%$ of full scale for the PIES's 6000-psi-rated pressure sensor).

In conventional PIES applications, early echoes recorded by the IES (i.e., echoes from a reflector within the water column that are not so close to the IES that they are excluded by the lockout time) are removed in the postrecovery data processing. Early echoes may arrive from schools of fish or squid (Watts et al. 2006) or air bubbles ( $\mathrm{Li}$ et al. 2009), or as described in section 3, from an ice-water interface. In these conventional applications, a single hourly $\tau$ value $\tau_{\text {surf }}$ is derived from each set of 24 pings using the quartile method ${ }^{1}$ (Kennelly et al. 2007) and represents only reflections from the sea surface (i.e., the air-sea interface). The range in a typical $\tau_{\text {surf }}$ time series is $\pm 5 \times 10^{-3} \mathrm{~s}$ and the variability in $\tau_{\text {surf }}$ is generally dominated by variability in the temperature and salinity structure of the water column (rather than changes in $L$ ).

\footnotetext{
${ }^{1}$ In the quartile method, $n$ echoes in an hour that fall within the range expected for reflections from the sea surface are identified $(n \leq 24)$. These $n$ samples are sorted by ascending $\tau$. Then $n / 6$ values are averaged-beginning with the last sample in the first quartile—to give a single, hourly $\tau$ value. For example, for $n=24$ the sixth through ninth smallest $\tau$ values in the hour are averaged to produce that hour's $\tau_{\text {surf. }}$.
}

\section{b. Bottom pressure}

The quantity $P_{b}$ provides a measure of the vertical surface-to-bottom distance $D$ between the PIES and the air-sea interface. Unlike tall moorings, which can experience significant mooring blowdown in strong currents, a PIES in its rigid stand is fixed relative to the seafloor. Because of concern about strong sedimentation in Sermilik Fjord, the PIES discussed in section 4 was deployed with a $1.5-\mathrm{m}$ mooring line attached to an anchor weight, rather than with a rigid stand. The motion from such a short mooring line gives vertical displacements less than $0.14 \mathrm{~m}$ for a $25^{\circ}$ tilt and may be neglected, even in strong bottom currents, for the applications described here. Since sedimentation did not appear to hamper instrument recovery from the site in Sermilik Fjord, however, future deployments here can use a rigid stand, thereby eliminating this small source of variability in $P_{b}$ and uncertainty in $D$.

\section{Identifying icebergs and sea ice in an IES's acoustic travel-time record}

In contrast to the processing and averaging done for conventional IES applications, the methods to detect and characterize ice developed below exploit the individual echoes from each hourly set of 24 pings. In particular, the so-called early echoes-namely, those that echo from strong reflectors other than the sea surface-are examined to identify the presence of icebergs and sea ice. In addition, the high sampling rate (four pings every $10 \mathrm{~min}$ ) enables the use of echoes from an iceberg to estimate its drift speed and, in some cases, constrain the ice draft.

An IES transducer (Fig. 2) ensonifies the volume around the IES with the $-3-\mathrm{dB}$ contour (half-power point) defining an approximate cone with angle $\theta=90^{\circ}$ (Figs. 3a,b). If there are no strong reflectors within the water column, the earliest four echoes from each burst of four pings are those reflected from the sea surface directly above the IES and $L$ in Eq. (1) is simply the water depth $D$. However, icebergs and land-fast sea ice can be detected with an IES and each has a unique signature in the $\tau$ record as described next.

\section{a. Detection of icebergs}

When an iceberg moves into the volume ensonified by the PIES, the IES may record reflections from the icewater interface rather than from the air-water interface whenever $r<D$ ( $r$ is the distance between the iceberg keel and the IES, and the $r=D$ surface is indicated by the gray dashed curve in Fig. 3a). In practice, echoes arriving at the IES transducer from the edges of the 
(a)

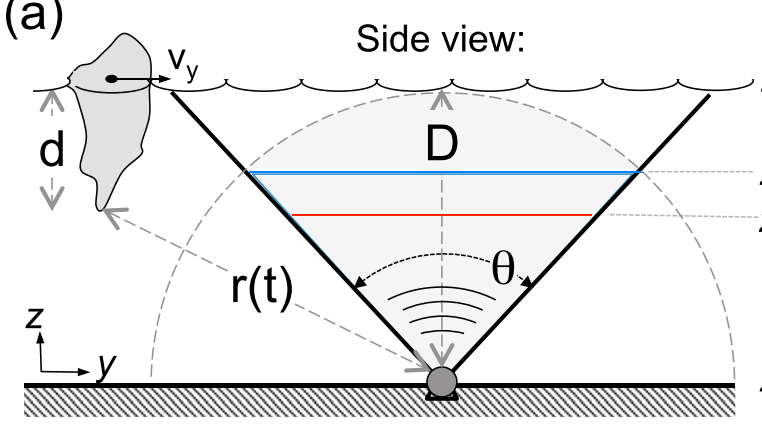

(b)

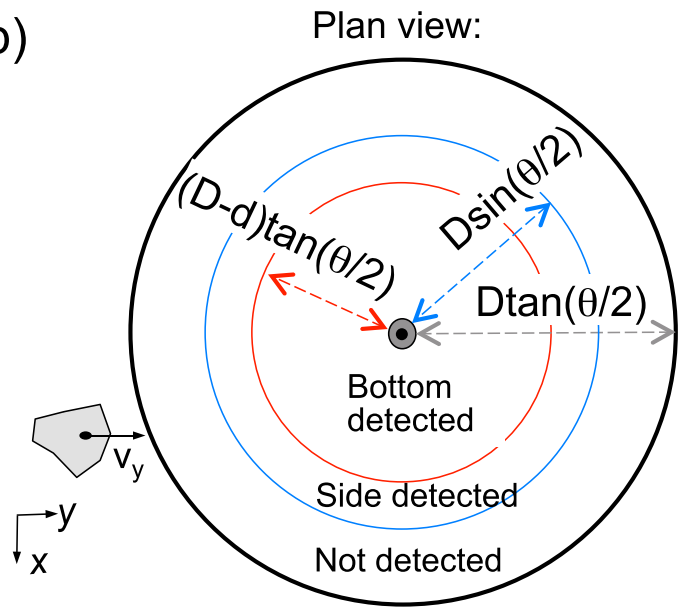

(c)
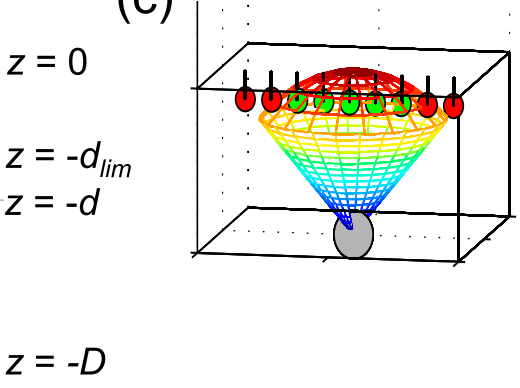

$z=-D$

FIG. 3. (a) Schematic depicting a side view of the cone-shaped volume (inside the heavy black lines, indicating the approximate -3-dB surface) ensonified by the four pings emitted during an IES burst. Also shown is a deep iceberg $\left(d>d_{\text {lim }}\right)$ moving with drift speed $v_{y}\left(v_{x}=0\right)$ that is about to enter the ensonified volume. (b) Plan view of the volume in (a) at the sea surface, where $z=0$ (black circle), at $z=-d_{\lim }$ (blue), and at $z=-d$, the base of the iceberg keel (red). Labeled areas indicate regions where the iceberg can be detected as the iceberg moves through the ensonified cone. (c) Schematic of a shallow point iceberg (represented by the vertical black lines) progressively passing through the region ensonified by the IES. When the iceberg is within the detection volume, the deepest point on the keel bottom (indicated by the green dots) will be detected by the IES. (d) Corresponding reflection curve (for a case with $D=1000 \mathrm{~m}$ and $\left.\bar{c}=1485 \mathrm{~m} \mathrm{~s}^{-1}\right)$ : red dots denote reflections from the sea surface and green dots are successive reflections from the same (deepest) point on the bottom of the keel.

volume indicated with the $r=D$ surface are beyond the $-3-\mathrm{dB}$ level and are so weak that they are not detected by the IES. Ice detection generally occurs when the reflector is within the gray-shaded volume indicated in Fig. 3a (a cone topped with a truncated sphere). As an iceberg keel drifts horizontally through this "detection volume" (Fig. 3b), $L=r(t)$ in Eq. (1) and the measured $\tau$ first decreases as the reflector approaches the IES and subsequently increases as the distance to the reflector increases (e.g., Fig. 3d). Finally, the iceberg exits the detection volume and the IES resumes recording reflections from the sea surface $(L=D)$. This smooth pattern contrasts with early echoes from biological material or bubbles, which tend to have more randomly distributed $\tau$ values. Furthermore, icebergs can cause very large variations in $\tau$ as they move past the IES; the $\tau$ change detected during an iceberg's transit can be $0.5 \mathrm{~s}$, which is two orders of magnitude larger than the range in conventional IES acoustic travel-time records associated with echoes from the sea surface.

The shape of the reflection curve ( $\tau$ vs time $t$ ) for an iceberg depends on $\bar{c}, D$, the trajectory of the iceberg, and the submarine shape of the iceberg. The latter is not necessarily related in a simple way to the subaerial shape of the iceberg by which icebergs are conventionally categorized (e.g., Fequest 2005, 2-17). In the following, icebergs are considered based on the characteristics of their keels, namely, the maximum depth reached by the keel and how peaked or flat the base of the keel is. Based on this, icebergs are categorized as shallow versus deep and point versus slab, as discussed further below.

One can consider two end-member submarine shapes for "shallow" icebergs. Here shallow icebergs refer to 


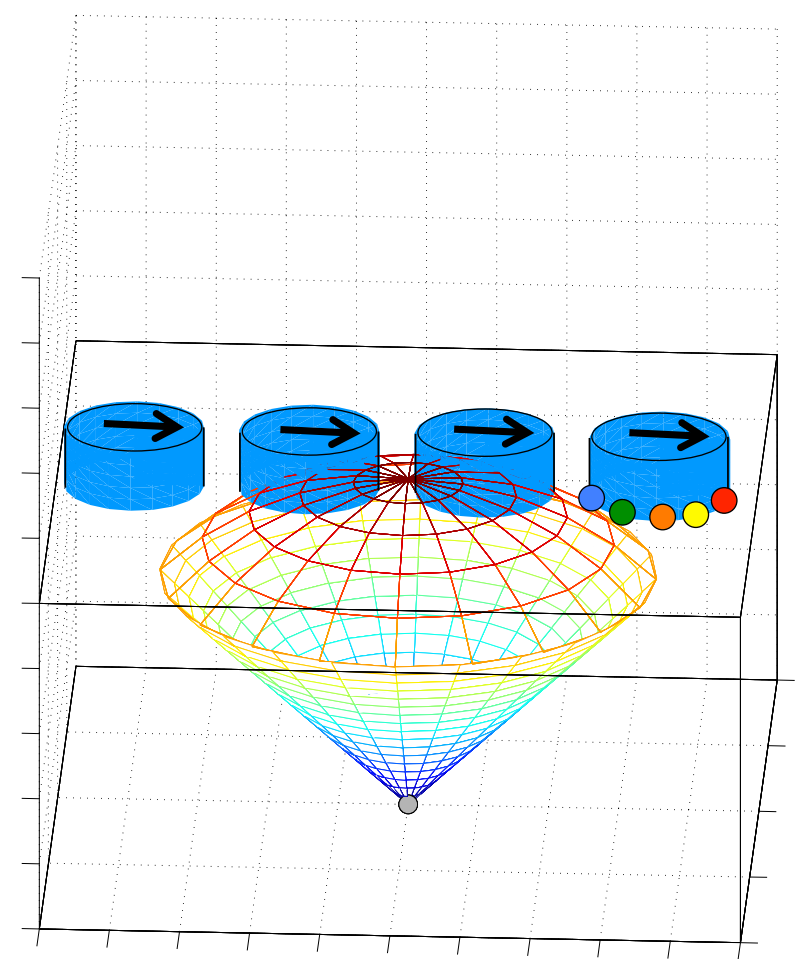

FIG. 4. Schematic of a shallow $\left(d<d_{\text {lim }}\right)$ slab iceberg moving through the IES's detection volume. Colored dots indicate the locations on the iceberg keel that are detected (sequentially from red to blue). In this example, the iceberg does not pass directly above the IES. Arrows indicate the iceberg's velocity.

those icebergs whose keels do not extend below the rounded top of the detection volume (Fig. 3a). A shallow iceberg's draft $d$ is less than $d_{\text {lim }}$, where

$$
d_{\lim }=D[1-\cos (\theta / 2)] .
$$

These end-member shapes are a shallow point iceberg (Fig. 3c) and a shallow flat-bottomed, slab iceberg (Fig. 4). For both end-member shapes, the $\tau$ record is due to reflections off the bottom (rather than the side) of the iceberg keel. There is, however, some uncertainty in $d_{\lim }$ because the spatial extent of the detection volume (i.e., $\theta$ ) depends on (i) an IES's transducer transmission and detection patterns, (ii) an IES's echo detect threshold, and (iii) an IES's acoustic power output. For $D=860 \mathrm{~m}$, for example, a $\pm 1^{\circ}$ uncertainty in $\theta$ gives a 10-m uncertainty in $d_{\mathrm{lim}}$, which is similar in magnitude to the uncertainty in draft estimate that is associated with temporal changes in $\bar{c}$; see section $2 \mathrm{a}$.

For a shallow point iceberg, $\tau$ is always from reflections off the same (deepest) point on the keel (green dot in Fig. 3c). As that point moves through the ensonified region, $r$ changes according to

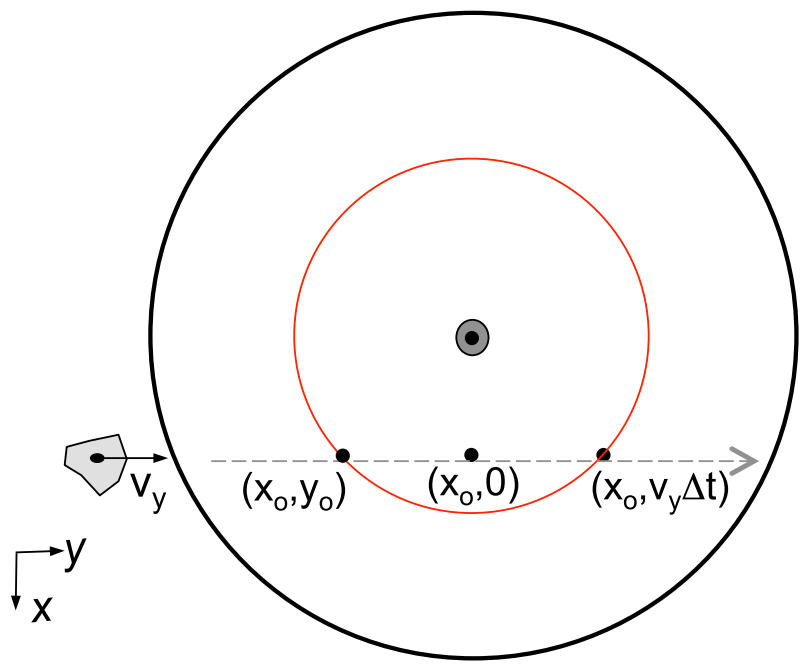

FIG. 5. Plan view of the detection of a shallow $\left(d<d_{\text {lim }}\right)$ point iceberg moving with constant velocity $v_{y}$. The iceberg is detected when it passes into the red circle. Red and black circles are as in Figs. 3a,b.

$$
r(t)=\sqrt{\left[x_{0}+v_{x}\left(t-t_{0}\right)\right]^{2}+\left[y_{0}+v_{y}\left(t-t_{0}\right)\right]^{2}+(D-d)^{2}} .
$$

Here $v_{x}$ and $v_{y}$ are the $x$ and $y$ components of iceberg velocity, time $t$ is 0 when $r$ is minimum (i.e., when the iceberg keel is at its closest approach to the IES and $\left.\tau=\tau_{\min }\right)$, and $x_{0}$ and $y_{0}$ are the horizontal position of the deepest part of the iceberg keel relative to the IES when it is first detected at $t=t_{0}$ (Fig. 5). If $v_{x}$ and $v_{y}$ are constant, then the points on the reflection curve for a shallow point iceberg (Fig. 3d) can be used to determine iceberg speed (discussed further in section $3 \mathrm{~d}$ ) and the iceberg is detected for a total time interval $\Delta t=2\left|t_{0}\right|$.

In contrast, as a shallow slab iceberg moves through the detection volume, each detected echo arrives from a different point on the underside of the iceberg (Fig. 4) and the shape of the reflection curve depends on the shape of the iceberg's horizontal cross section. If the slab passes directly over the IES along the centerline of the detection volume, then $\tau$ is constant, as the slab bottom is overhead, and it is possible to determine $d$ explicitly, rather than just a range of possible drafts (see section $3 b$ ).

In practice, icebergs in Greenland fjords are not perfect slabs, not perfect points, and often not shallow. If an iceberg is deep $\left(d>d_{\text {lim }}\right)$, like the iceberg shown in Fig. 3a, then the echoes will be from different points along the side of the keel until the deepest point of the keel moves into the detection volume (as indicated by the area between the blue and red circles in Fig. 3b). For 
all icebergs, however, that part of the iceberg's reflection curve recorded as the IES is tracking a constant point moving at constant velocity (namely, when the deepest part of the iceberg keel is within the red circle in Fig. 3b) can be used to estimate iceberg speed (see section 3d). In contrast to Antarctic icebergs, which tend to be large and tabular, and may have relatively flat bottoms, many icebergs in Sermilik Fjord can be approximated as point icebergs (i.e., the cross section of the bottom of the keel is small relative the cross section of the volume ensonified by the PIES).

\section{b. Detection of land-fast sea ice}

In addition to the new methods for iceberg detections described above, an IES can be used to detect periods of land-fast sea ice over the instrument. In contrast to the icebergs (whose $\tau$ range is generally much larger than the range associated with reflections from the sea surface), sea ice is relatively thin, so the $\tau$ range expected for reflections from the ice-sea interface overlaps the expected range for reflections from the air-sea interface. For echoes from the air-sea interface, there is scatter in the measured $\tau$ due to surface waves (evident in the $\tau$ record shown in Fig. 6a for days prior to 421 and after 430); this is one reason why the 24 pings in an hour are used to generate a single hourly $\tau_{\text {surf }}$ value in conventional IES applications. However, a covering of sea ice can suppress these surface waves and the resulting scatter in $\tau$. As a consequence, the distinguishing feature of $\tau$ recorded while there is land-fast sea ice directly above the IES is the remarkably small variance in $\tau$ over each burst of four pings (see the low standard deviation of $\tau$ between day 421 and day 430 in Figs. 6b,c). Even PIES users who are not interested in sea ice per se should be aware of this signal, so that they can manually filter periods of sea ice cover from their PIES data records to avoid low biases in the acoustic travel times, since this is not accounted for in the existing postrecovery PIES processing software. With that software, users can first winnow the data to remove obvious late echoes and any early echoes due to deep reflectors before examining the standard deviation of the remaining $\tau$ values in each burst.

\section{c. Constraining iceberg draft and sea ice thickness estimates}

If the deepest point on an iceberg keel moves directly over the IES, then the minimum $\tau$ in the iceberg's reflection curve $\left(\tau_{\min }\right)$ can be used with Eq. (1) to determine the iceberg's draft: $d=D-r$. However, it is not possible to establish a priori whether this part of the iceberg has in fact passed directly over the IES, except for the case of a slab iceberg whose $\tau$ is constant while
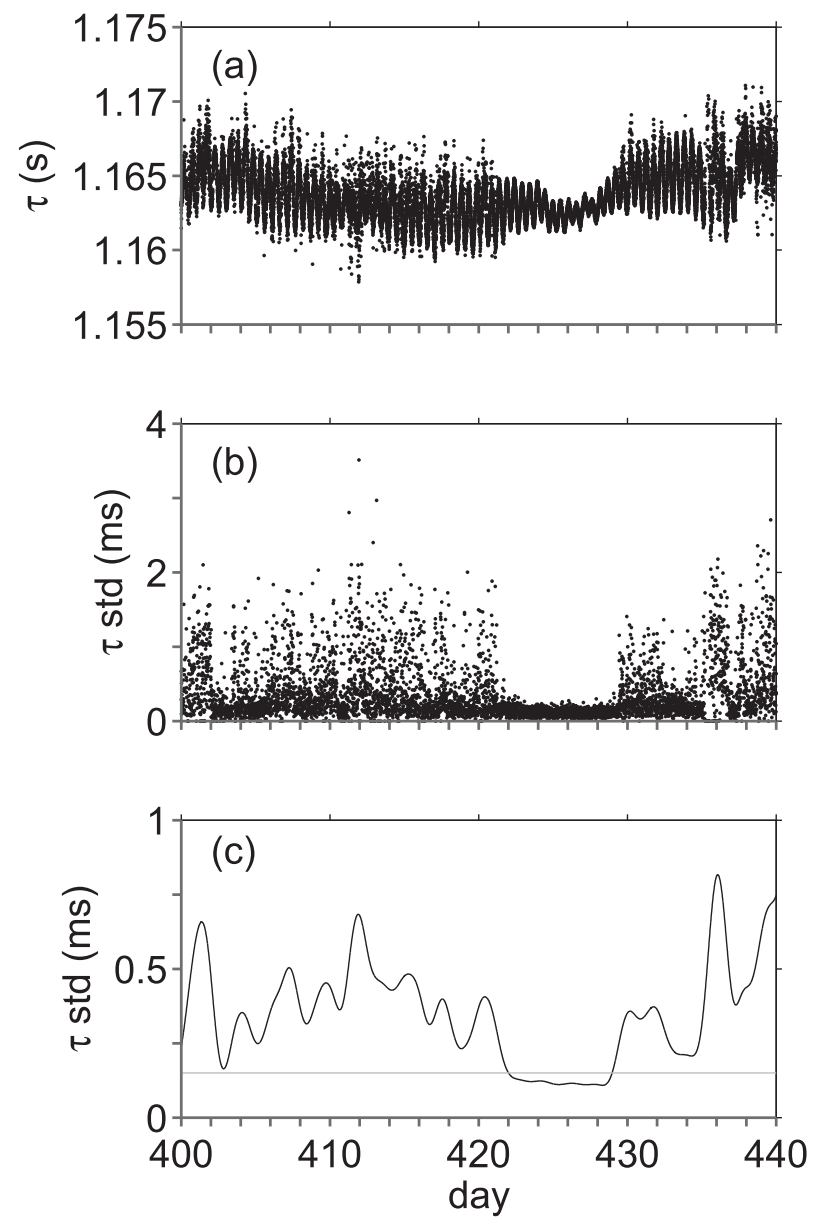

FIG. 6. (a) Time series of individual echoes showing $\tau$ for each ping in the four-ping bursts over a 40-day period (icebergs and other early echoes have been removed from the record, but the tidal signal remains in the record). (b) Standard deviation of $\tau$ for each four-ping burst. (c) A 2-day low-pass-filtered version of (b) (black) with a threshold at $0.15 \mathrm{~ms}$ indicated (gray); sustained standard deviation below this level indicates a period of land-fast sea ice cover over the IES (this interpretation is confirmed by concurrent satellite imagery; see section 4c). Tick marks on the $x$ axes are at 2-day intervals.

the flat part of iceberg keel is directly overhead (i.e., when the shortest path between the reflector and the IES is vertical). In general, $\tau_{\min }$ usually provides only a lower bound on $d$. To help constrain $d$, we first define an equivalent draft $d_{\text {eq }}$, which is the draft that would be associated with a given reflection curve if the iceberg had passed directly over the IES:

$$
d_{\mathrm{eq}}=D-\frac{\tau_{\min } \bar{c}}{2} .
$$

This provides a lower bound on the draft: $d \geq d_{\text {eq }}$.

For point icebergs, one can also obtain an upper bound on $d$. There are two cases to consider. In the first case, all the points on the reflection curve fall on the 
curve defined by Eq. (3). This indicates that the detected reflections are all from the deepest point on the keel, in which case the iceberg must be moving through the upper part of the detection volume (Fig. 3c) and its draft falls in the range:

$$
d_{\mathrm{eq}} \leq d \leq d_{\mathrm{lim}}
$$

In the second case, the points on the reflection curve do not fall on a single curve defined by Eq. (3) because the iceberg is deep $\left(d \geq d_{\text {lim }}\right)$. In this case, the initial points and final points on the reflection curve arrive from the sides of the iceberg. From geometric considerations (i.e., by comparing the detection surface-defined by $D-d_{\text {eq }}$, which is a sphere with radius $D-d_{\text {eq }}$ centered on the IES - with the volume ensonified by the IES, which is a cone with angle $\theta$ ), one can obtain the upper bound on $d$ such that

$$
d_{\lim } \leq d \leq D-\left(D-d_{\mathrm{eq}}\right) \cos (\theta / 2) .
$$

These ranges are indicated graphically in Fig. 7.

For a slab iceberg, the reflection curve is a convolution of the iceberg's velocity and bottom shape, so it is not possible to determine unambiguously whether it is shallow or deep. So, in general, for slab icebergs one can obtain only a lower bound on $d: d_{\text {eq }} \leq d$, except for those cases when $\tau$ is constant, indicating that the slab passes directly over the IES, in which case $d_{\mathrm{eq}}=d$ and Eq. (4) can be used to calculate draft.

As discussed in section 4a, the presence of land-fast sea ice over the IES can be detected, even if it is quite thin, because of the characteristic low variance in $\tau$ associated with each burst of pings. But uncertainty in the sea ice draft based on IES records is on the order of 1$10 \mathrm{~m}$, due to the dependence of sound speed on the seawater's time-varying temperature and salinity profiles (Del Grosso 1974), which sets $\bar{c}$ in Eq. (1). This uncertainty also plagues iceberg draft estimates, but it is quite small relative to the other uncertainties described above and plotted in Fig. 7. These changes in seawater properties occur both at low frequency (due to, for example, seasonal heating and cooling or interannual variability in water mass properties) and at high frequency (due to internal waves heaving and shoaling the pycnocline). This $1-10-\mathrm{m}$ uncertainty in draft is large relative to the sea ice draft, which is itself typically less than $1 \mathrm{~m}$ thick. However, if the variability in $\bar{c}$ is primarily low frequency, one possible method to reduce the uncertainty in sea ice draft estimates is to identify reflections from the sea surface just before and just after sea ice is present to better constrain $\bar{c}$ during the ice-covered period. In practice, many efforts seek to measure sea ice thicknesses over long periods during

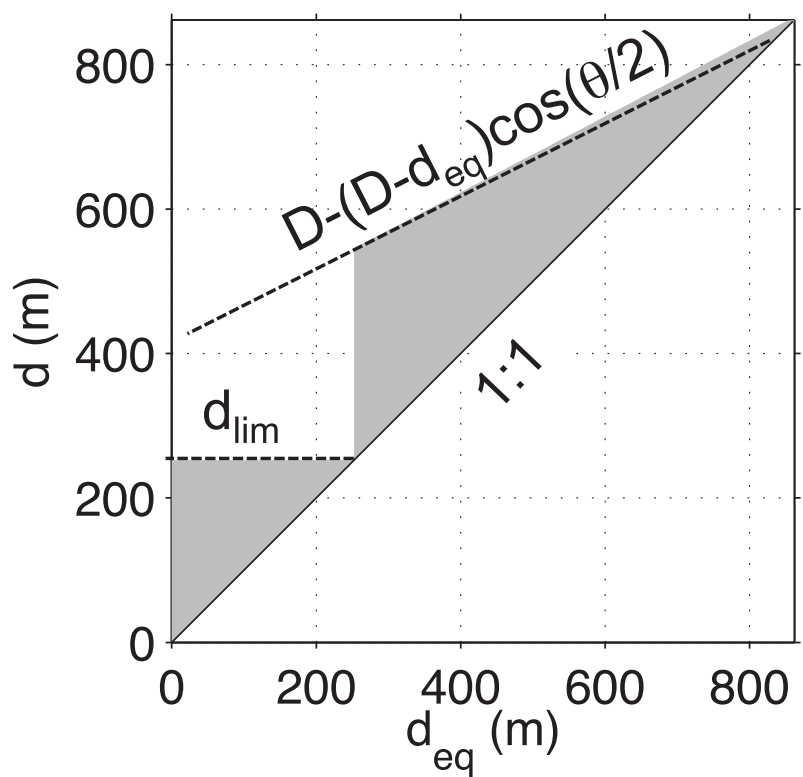

FIG. 7. Range in possible iceberg draft values $d$ (shaded) as a function of $d_{\text {eq }}$ for a point iceberg [ $d_{\text {eq }}$ is calculated from the measured $\tau_{\min }$ using Eq. (4)]. For the example plotted here, $D=$ $862 \mathrm{~m}$ and $\theta=90^{\circ}$, so $d_{\mathrm{lim}}=252 \mathrm{~m}$ [Eq. (2)]. (Note that uncertainty in $\theta$, discussed in section $3 \mathrm{a}$, does lead to uncertainty in the upper limit of the $d$ range; for the case shown here and for $\pm 1^{\circ}$ uncertainty in $\theta$, this is about $10 \mathrm{~m}$.)

which there are no intervening open-ocean condition to constrain $\bar{c}$, so this method to reduce uncertainty in PIES-derived sea ice draft estimates likely will have only restricted applicability (e.g., limited to the edges of large ice sheets or measurements in fjords with only intermittent sea ice coverage, or limited to regions where there is independent data from nearby moorings about the ocean's temperature and salinity profiles). For most applications, upward-looking sonars likely remain the more practical method to detect and measure thickness of the sea ice (e.g., Behrendt et al. 2011; Melling 1998), though in iceberg-rich fjords like Sermilik Fjord, upwardlooking sonars are prone to damage by iceberg keels, since they are moored within a few $100 \mathrm{~m}$ of the sea surface.

\section{d. Determining iceberg speed}

If an iceberg moves with constant velocity as it passes through the IES's field of view, then its drift speed $s$ can be determined if the reflections arrive from a constant location on the keel for at least that part of the $\tau$ record centered about $\tau_{\min }$. (Iceberg speed cannot be determined for slab-shaped icebergs because subsequent reflections are continually from different points on the keel; see Fig. 4.) In general,

$$
s=\left(v_{x}^{2}+v_{y}^{2}\right)^{1 / 2} .
$$



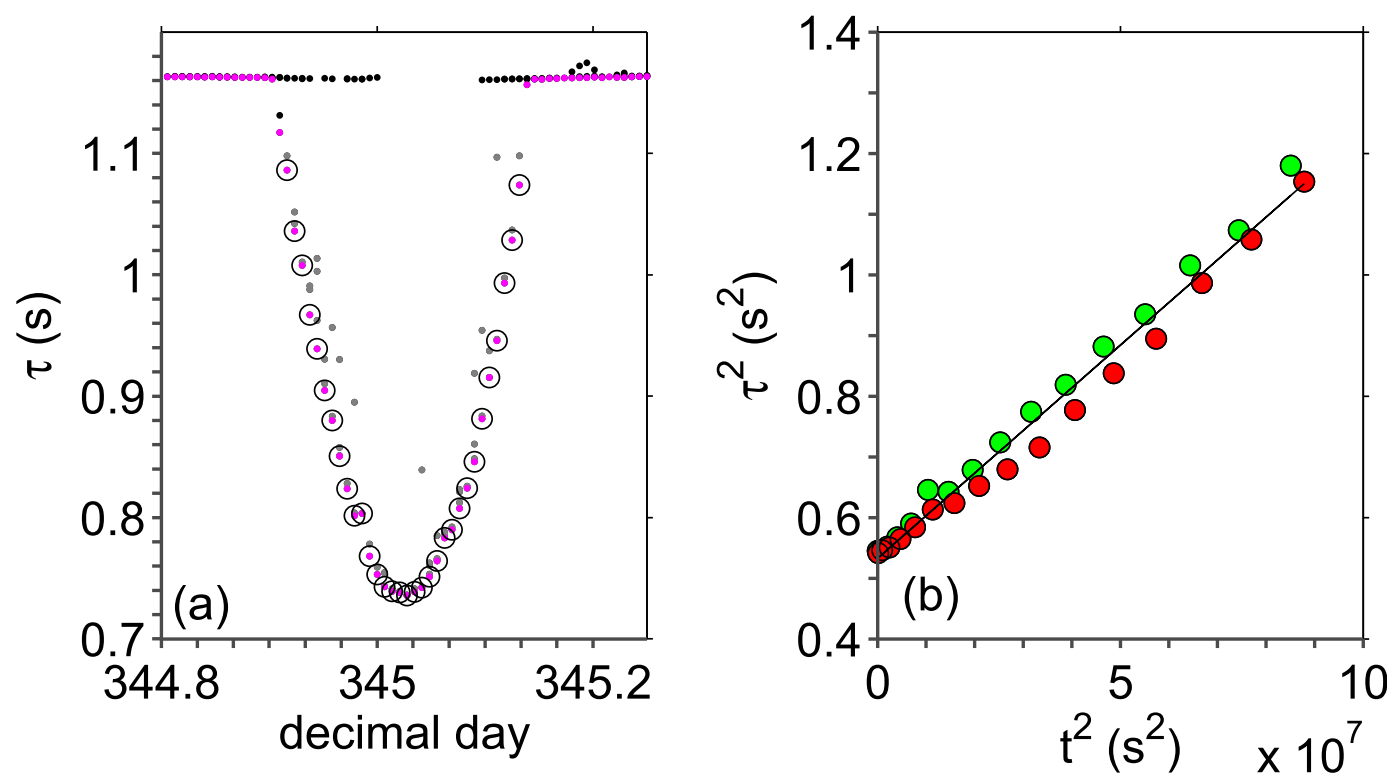

FIG. 8. (a) Acoustic travel-time record during an iceberg detection. The earliest ping within each burst is highlighted in magenta (for echoes from the sea surface, the dots are essentially on top of one another at this scale). The early pings used to identify the iceberg speed in (b) are circled. (b) Plot of $t^{2}$ vs $\tau^{2}$. Green circles indicate the iceberg's approach toward the IES as it passes into the ensonified volume, and red circles indicate the iceberg's retreat as it exits the volume. Slope of the best-fit line is given by Eq. (10) and the intercept by Eq. (11). For this example $\tau_{\min }=$ $0.7318 \mathrm{~s}, d_{\mathrm{eq}}=320 \mathrm{~m}$, and $s=0.06 \mathrm{~m} \mathrm{~s}^{-1}\left(5 \mathrm{~km} \mathrm{day}^{-1}\right)$ using $\bar{c}=1485 \mathrm{~m} \mathrm{~s}^{-1}$.

For an iceberg moving at constant velocity, rearranging the terms in Eq. (3) and rotating the coordinate system so that $v_{x}=0, s=v_{y}$, and $y_{0}=v_{y} t_{0}$ gives

$$
r(t)^{2}=\left(x_{0}\right)^{2}+(D-d)^{2}+s^{2} t^{2} .
$$

Setting $r=L$ in Eq. (1) and combining this with Eq. (8) gives

$$
\tau(t)^{2}=\frac{4}{\bar{c}^{2}}\left[\left(x_{0}\right)^{2}+(D-d)^{2}\right]+\left(\frac{2 s}{\bar{c}}\right)^{2} t^{2} .
$$

With Eq. (9), the following procedure is used to determine iceberg speed from the $\tau$ record. First, the presence of an iceberg is established by examining the raw $\tau$ record for patterns of smoothly changing early echoes (presently, this procedure is not automated). For this, an iceberg keel must be in the IES's field of view for at least $30 \mathrm{~min}$ (i.e., during three bursts of four pings) to be identifiable. Very shallow icebergs or icebergs that pass far from the IES are not detected because they are in the field of view for too short a duration. Also, if several icebergs are within the IES's field of view at once, or if the iceberg shape is very complicated, then $\tau$ is difficult to interpret and drift speeds cannot be determined.

For each iceberg, a reflection curve (acoustic travel time vs time) is generated using the first echo from each set of four pings (Fig. 8a). The time when $\tau=\tau_{\min }$ in this reflection curve is defined as $t=0$. Some icebergs have clear signals on the leading edge of their reflection curve but not on the trailing edge (or vice versa), possibly because reflections from a steep iceberg edge have been scattered when the icebergs are just at the edge of the detection volume; for these icebergs $\tau_{\min }$ (and drift speed) cannot be determined unambiguously.

Next, the points that reflected from a constant location on the keel (i.e., from the bottom of the keel rather than the side) are identified as follows. All the points in the reflection curve are used to make a plot of $t^{2}$ against $\tau^{2}$ [Eq. (10)], a best-fit line to the data is generated, and the coefficient of determination $\left(R^{2}\right)$ is calculated (Fig. 8b). The plot is generated again by excluding the first and last points (which could be reflections from the side of a deep iceberg as it is moving into and out of the field of view) and the coefficient of determination is recalculated. This procedure is continually repeated by eliminating successive pairs of initial and final $\tau$ values until the set of echoes that gives the best fit is determined. In this way, the points that fall on a single curve described by Eq. (3), centered on $\tau_{\min }$ and reflecting off the deepest point on the keel at $z=-d$, are identified. If these points do indeed represent reflections from a single point on the deepest part of the iceberg keel in the IES's field of view, then the slope $m$ of the 

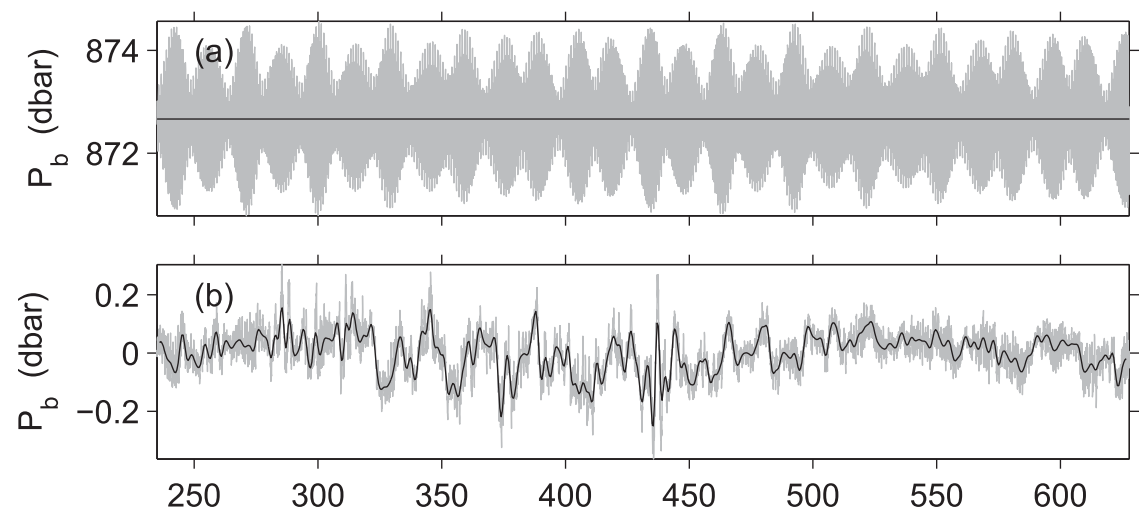

FIG. 9. The $P_{b}$ record from PIES at G1. (a) The hourly total pressure (gray) with the recordlength average indicated (black). (b) The (detided) hourly (gray) and 2-day low-pass-filtered (black) pressure time series with the record mean removed.

best-fit line for $t^{2}$ versus $\tau^{2}$ [Eq.(9)] is related to the iceberg's drift speed:

$$
m=\left(\frac{2 s}{\bar{c}}\right)^{2}
$$

A change in slope on the plot of $t^{2}$ against $\tau^{2}$ indicates either a change in iceberg velocity or that the reflections are no longer coming from the same location on the keel. In either case, the procedure described above is intended to eliminate these points to determine a best estimate of iceberg drift speed without a priori knowledge of the depth of the iceberg or how far the deepest point on the keel passed from the IES.

The intercept in the plot of $t^{2}$ against $\tau^{2}$ is at $\left(\tau_{\min }\right)^{2}$ and from Eq. (9):

$$
\tau_{\min }=\frac{2}{\bar{c}}\left[\left(x_{0}\right)^{2}+(D-d)^{2}\right]^{1 / 2} .
$$

For an iceberg that passes directly over the IES, $x_{o}=$ 0 and this intercept can be used to determine $d$, but in general, icebergs do not pass directly over the IES and $x_{o}$ is not known.

\section{Results from Sermilik Fjord}

\section{a. Study site}

In August 2011 a PIES was deployed on the seafloor at $\sim 860$-m depth in Sermilik Fjord (for fjord details, see Straneo et al. 2010, 2011; Sutherland et al. 2013; Enderlin et al. 2014; Jackson et al. 2014) at $65^{\circ} 54^{\prime} \mathrm{N}$, $37^{\circ} 54^{\prime} \mathrm{E}$, roughly in the center of the fjord, which is approximately $6-8 \mathrm{~km}$ wide and $65 \mathrm{~km}$ long (Fig. 1 ). The PIES at this site, G1, collected time series of $P_{b}, T_{b}$, and $\tau$ for 13 months until it was recovered in September
2012. Data collected by the PIES are used here to demonstrate the use of PIESs in ice-infested fjord environments. Detailed analyses of the records and the scientific implications will be presented elsewhere (A. Silvano et al. 2015, unpublished manuscript; F. Straneo et al. 2015, unpublished manuscript). Here the general features of the $P_{b}$ and $\tau$ records are described, and then the detection of icebergs and sea ice in Sermilik Fjord using the methodology from section 3 is discussed.

\section{b. PIES records from Sermilik Fjord}

At $\mathrm{G} 1$, the record-average $P_{b}$ is $872.7 \mathrm{dbar}$, which corresponds to an average instrument depth of $D=$ $862 \mathrm{~m}$. The dominant signal in the $P_{b}$ record (Fig. 9) is tidal and there is a clear spring-neap cycle in the record. During spring tide, the tidal range in $D$ reaches $\pm 1.8 \mathrm{~m}$ and during neap tides the range is $\pm 0.3 \mathrm{~m}$. These tides in Sermilik Fjord lead to a measureable contribution to variability in acoustic travel time that is associated with changes to $L$ [Eq. (1)]. During spring tide, the tidally driven $\tau$ variability is $\pm 1.2 \mathrm{~ms}$. While this has a negligible effect on the identification of icebergs and estimates of iceberg speed-for which the $\tau$ range during iceberg detection is approximately $0.5 \mathrm{~s}$ - the tidal contributions are a significant component of the total $\tau$ signal associated with reflections from the sea surface and shallow sea ice.

At site $\mathrm{G} 1$, reflections from the sea surface are expected to fall in the range $\tau=1.1643 \pm 0.0042 \mathrm{~s}$ based on the following considerations: (i) the mean depth of the PIES, (ii) the range of $\bar{c}$ calculated from the speed of sound in seawater (Del Grosso 1974), and (iii) the tidal contribution to $D$. The $P_{b}$ record is used to determine (i) and (iii), and historical hydrography from Sermilik Fjord (e.g., Straneo et al. 2012; Sutherland et al. 2013) 

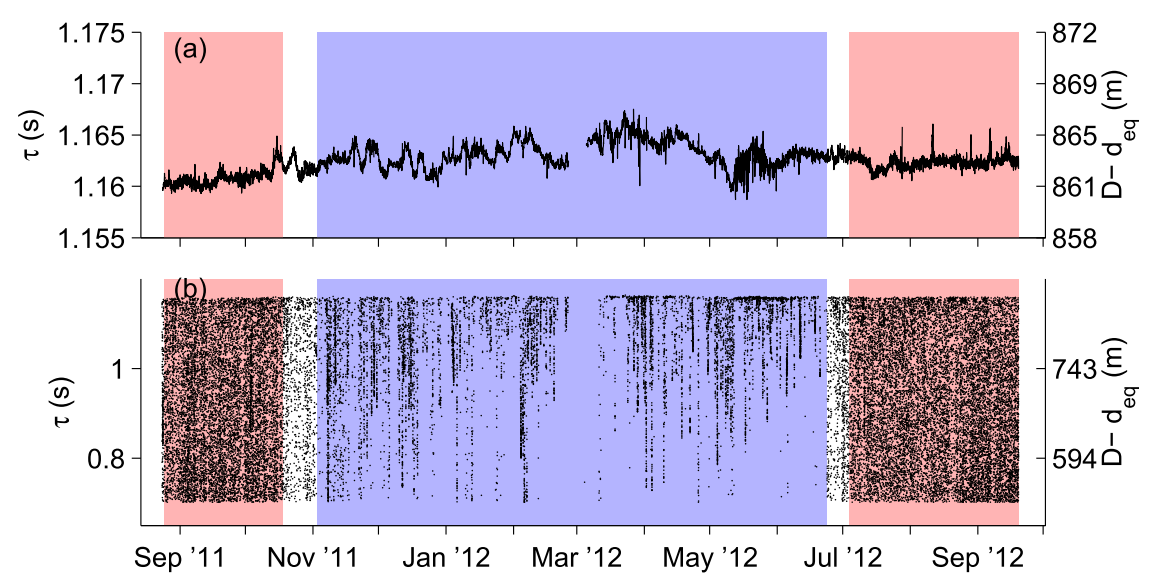

FIG. 10. Acoustic travel time at site G1. (a) The hourly, detided $\tau_{\text {surf. }}$ (b) Early echoes. Lockout time was set to $0.7021 \mathrm{~s} ; y$-axis labels on the right are derived from $\tau$ with $D=862 \mathrm{~m}$ and $\bar{c}=1485 \mathrm{~m} \mathrm{~s}^{-1}$. Red shading indicates the warm months, where there are frequent, random early echoes; and blue indicates the cold months, when there are fewer early echoes and it is possible to identify icebergs (see section $4 b$ ).

is used to determine (ii). Indeed, most data points in the $\tau$ record $(77 \%)$ do fall within this expected range, and these provide enough data to allow reliable estimates of the hourly averaged echo times from the sea surface $\tau_{\text {surf }}$ during almost the entire record.

The $\tau_{\text {surf }}$ time series is obtained from the PIES's data records via the conventional postrecovery $\tau$ processing procedures using the IES data processing code developed and provided by the PIES manufacturer (the University of Rhode Island; see Kennelly et al. 2007) with a few additional steps. Although the software procedure detects most icebergs automatically through the software's despiking routines, a few icebergs in the record are identified manually and hand edited to remove them from the record of surface echoes. Reflections from land-fast sea ice, however, are not identified automatically through the conventional data processing software, since their $\tau$ values fall within the range expected for sea surface echoes. These are characterized by periods when there is low $\tau$ variance within each set of pings and are also manually identified and removed. For G1, the 2-day low-pass-filtered time series of standard deviations is examined and $0.15 \mathrm{~ms}$ in this low-passed standard deviation record is chosen as the threshold to identify land-fast sea ice cover (Fig. 6c); this threshold is likely somewhat instrument dependent.

The resulting $\tau_{\text {surf }}$ time series is shown in Fig. 10a. The time series is complete except for a 2 -week stretch in March (discussed below). The record-average $\tau_{\text {surf }}$ is $1.1626 \mathrm{~s}$, consistent with the instrument depth $(D=862 \mathrm{~m})$ derived from the pressure record and $\bar{c}=1485 \mathrm{~m} \mathrm{~s}^{-1}$. Variability in $\tau_{\text {surf }}$ is largely due to changes in the vertical temperature profile and will be discussed in more detail elsewhere (F. Straneo et al. 2015, unpublished manuscript), but briefly, $\tau_{\text {surf }}$ exhibits (i) a low-frequency variability, likely due to the seasonal variability in the fjord's stratification; (ii) a tidal component due to changes in $L$ arising from the barotropic tide; and (iii) high-frequency variability, possibly due to internal waves.

In addition to the sea surface echoes, there are also clearly early echoes in the acoustic travel-time record (Fig. 10b). Different segments of the record are distinct, both in the rate of occurrence of early echoes and in the $\tau$ signatures of the early echoes. Frequent early echoes are constrained to the warm season and occur from the beginning of the record on 23 August 2011 through 18 October 2011 and again from 4 July 2012 through the end of the record on 19 September 2012. In these warm months, about $30 \%$ of the echoes are early (Fig. 10b, red shading). Furthermore, with few exceptions, the distribution of early echoes during these warm periods is random. This suggests that reflectors are distributed throughout the depth range sampled by the PIES (the upper $340 \mathrm{~m}$ of the water column; the lower part of the water column was excluded due to the lockout time setting). While most of these warm-month early echoes are likely not from icebergs, it is not clear what the sources of the reflections are, nor is it clear why the random early echoes are locked to the warm season. It is possible that the random noise is related to biological material that is tied to the amount of sunlight in the fjord, but this remains to be investigated further with ongoing PIESs deployments in the region. 

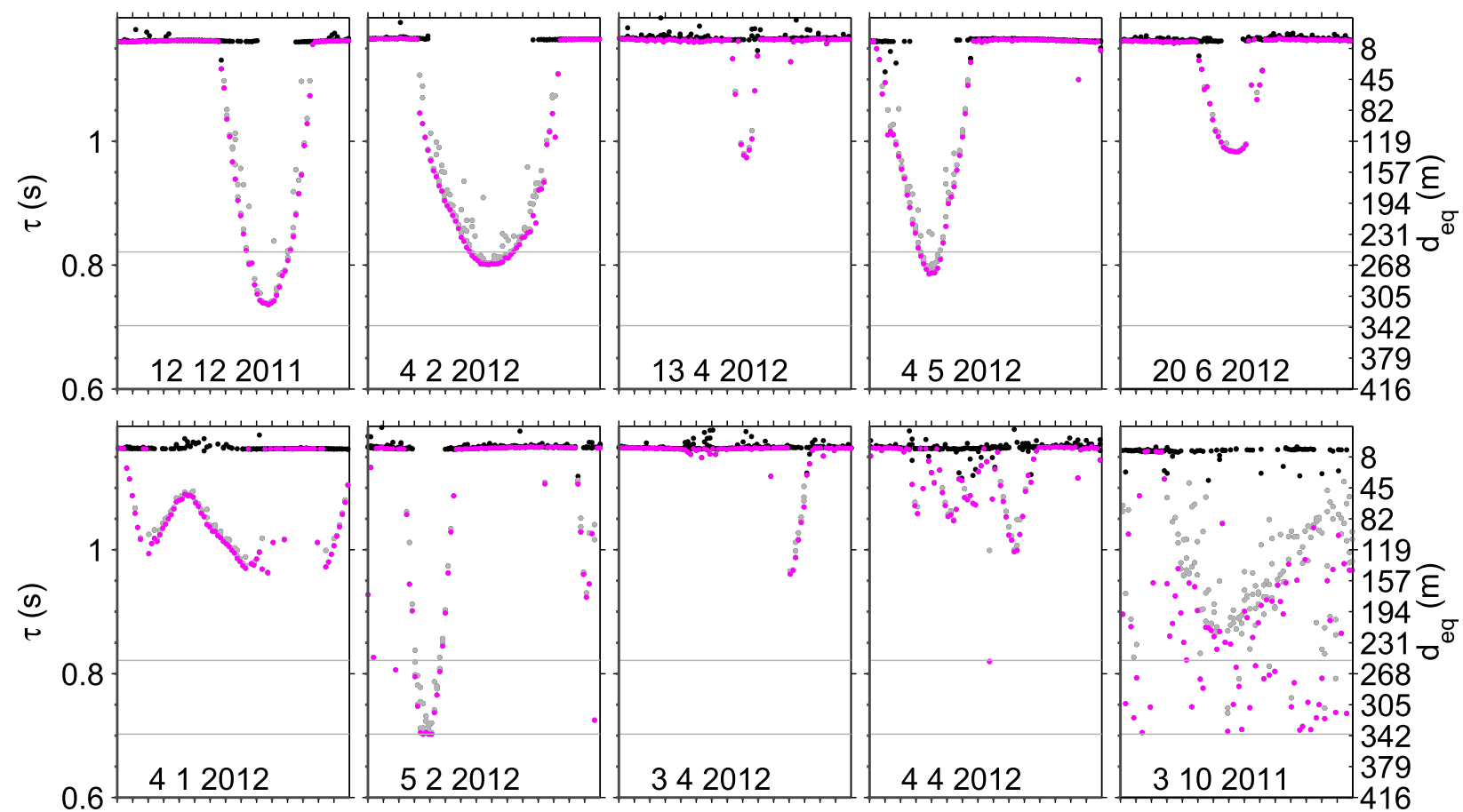

FIG. 11. Iceberg detection examples. The gray lines show the instrument's lockout time $\left(\tau=0.7021 \mathrm{~s}\right.$ or $\left.d_{\mathrm{eq}}=340 \mathrm{~m}\right)$ and $d_{\mathrm{lim}}(\tau=$ $0.8215 \mathrm{~s}$ or $\left.d_{\text {eq }}=252 \mathrm{~m}\right)$. The tick marks ( $x$-axes) are at 1-h intervals with $15 \mathrm{~h}$ shown in each frame. (top) Cases when an iceberg's drift speed and draft range can be estimated. (bottom) Detections with various factors that limit the ability to estimate drift speed and draft: on 4 January 2012, the reflection may be from an iceberg with a complicated keel shape (rather than a point iceberg); on 5 February $2012, \tau=$ $\tau_{\min }$ for three bursts at the value of the lockout time, so the iceberg's draft is likely deeper than $340 \mathrm{~m}$; on 3 April 2012, only the trailing edge of the iceberg is detected; on 4 April 2012, multiple icebergs are likely within the cone ensonified by the PIES and on 3 October 2011 (which is near the end of the warm period, shaded pink in Fig. 11); while there seem to be reflections from an iceberg keel, there are multiple early echoes from other reflectors throughout the water column and these obscure the iceberg reflections.

Abruptly, in mid-October 2011 the number of early echoes drops to $\sim 10 \%$ and between 3 November 2011 and 23 June 2012 fewer than $6 \%$ of the echoes are early (Fig. 10b, blue shading).

\section{c. Interpretation and results}

\section{1) ICEBERGS IN SERMILIK FJORD}

In contrast to most of the early echoes during the warm months, the early echoes between October and June are generally not randomly distributed in $\tau$ space. Rather, they occur in groups during which $\tau$ decreases before increasing again to values representative of reflections from the air-sea interface (e.g., Fig. 11, top row). As discussed in section $3 a$, this pattern is indicative of icebergs moving through the PIES's field of view.

During this 8.5-month period, an iceberg was in the PIES's field of view 285 times. Some of these detections may have been the same iceberg moving through the field of view more than one time in response to changes in the fjord circulation. In addition, during some detections, multiple icebergs were in the field of view at one time. Each detection of a single iceberg lasted for at least $30 \mathrm{~min}$ (the lower threshold necessary to distinguish an iceberg) and up to a maximum of $16 \mathrm{~h}$. Of the 285 detections, 90 cases likely had more than one iceberg in the field of view; see Fig. 12a for a histogram of the durations of the 195 detections when there was only one iceberg in the field of view at a time.

One of the deepest icebergs occurred on 5 February 2012 (Fig. 11) and its $\tau_{\min }$ corresponded to an equivalent depth of $d_{\mathrm{eq}}=340 \mathrm{~m}$. However, since the lockout time was set to $0.7021 \mathrm{~s}$, reflections from the portion of the keel that passed within $r=522$ were not detected, and this iceberg's draft was likely greater than $340 \mathrm{~m}$.

Speeds were determined for 178 of the detections using the procedure described in section $3 \mathrm{c}$. For the remaining 107 detections, however, speeds could not be established; some examples are shown in Fig. 11 (bottom row). Speeds are ambiguous for those cases where early echoes were detected only on one-half of the reflection curve (e.g., 3 April 2012), for cases where fewer than four points 

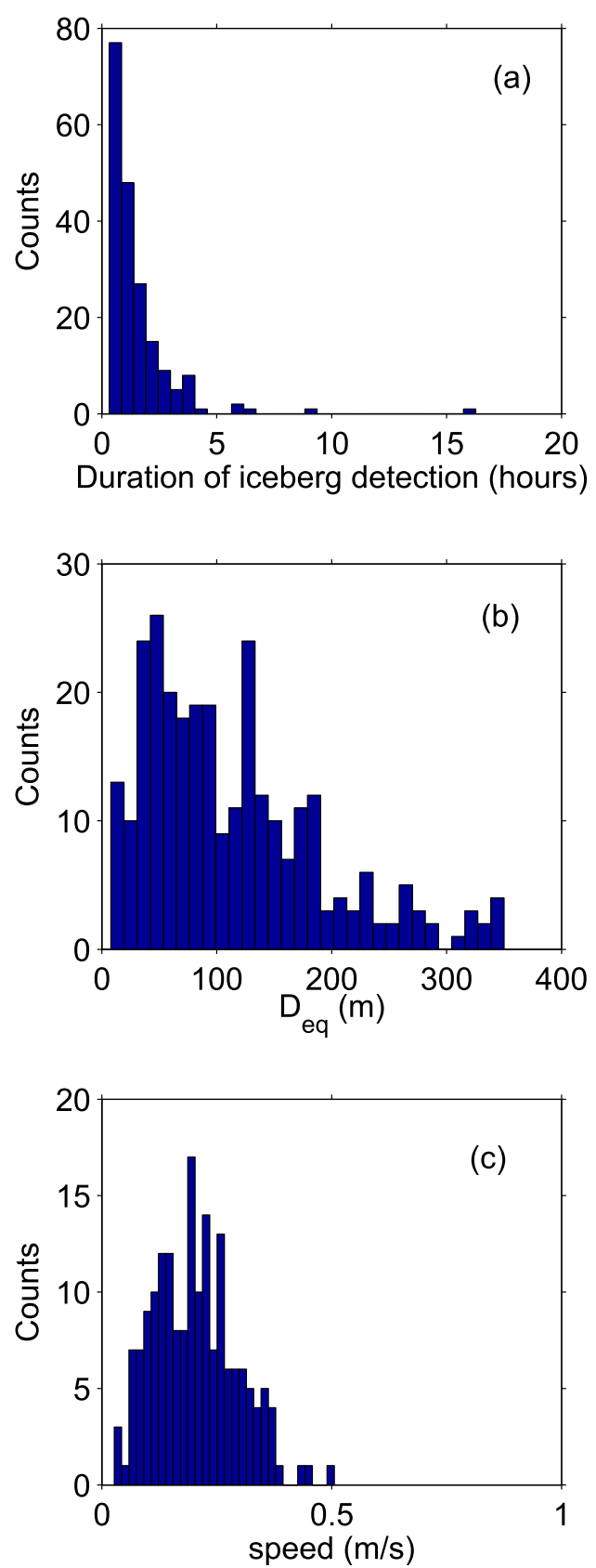

FIG. 12. Statistics of iceberg detections. (a) Duration of iceberg detections for the 195 cases when there was clearly only one iceberg keel within the IES's detection volume. During most of the remaining 90 detection events, it appears likely that one iceberg did not exit the detection volume before another one entered; however, a single iceberg with a complicated keel shape cannot be ruled out for these cases. (b) Calculation of $d_{\text {eq }}$ from the minimum $\tau$ occurring during each of the total (285) detection events. (c) Drift speed for the 178 cases where speed could be determined (not every detection included in the top panel has a clear $\tau_{\min }$ or a welldefined slope on a $\tau^{2}$ vs $t^{2}$ plot, so $d_{\text {eq }}$ and drift speed could not be determined for each detection of a single iceberg).
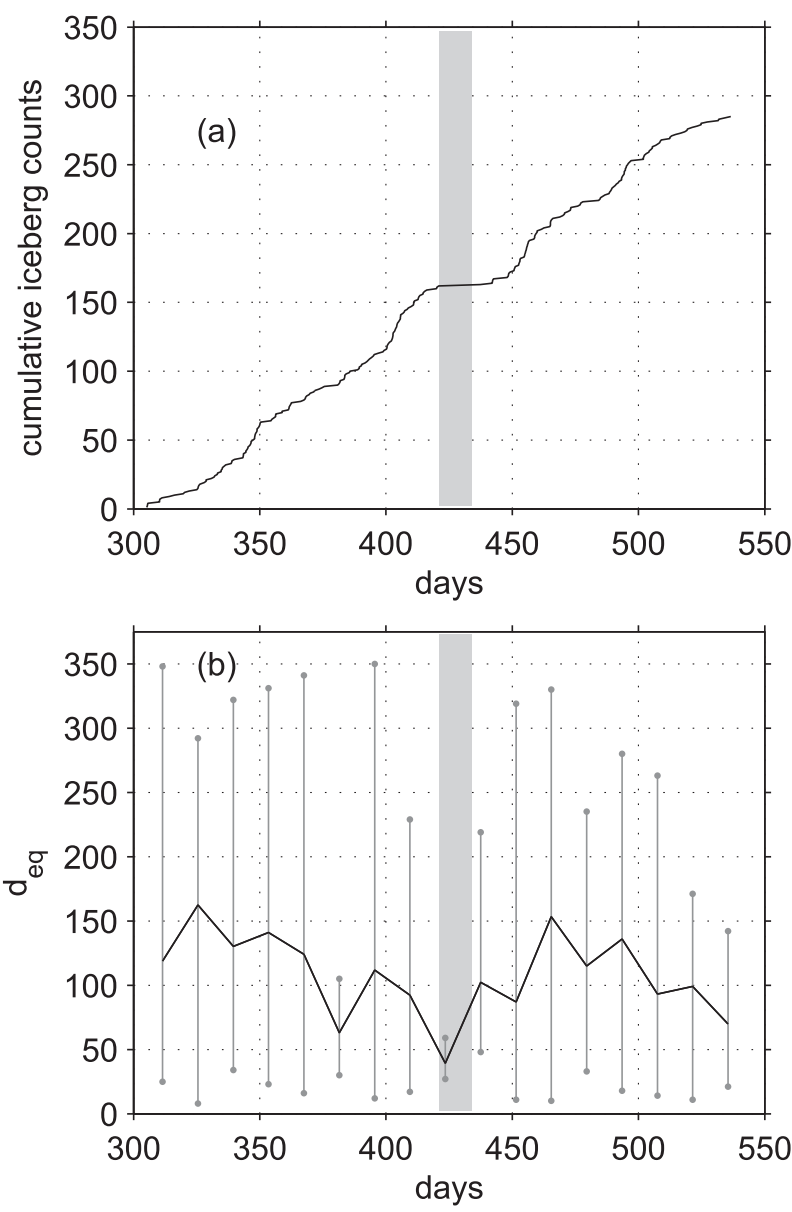

FIG. 13. (a) Cumulative iceberg counts as a function of time (days since 1 Jan 2011) to a total of 285 detections (some may have multiple icebergs in a count, or a complicated keel geometry). (b) Average, maximum, and minimum $d_{\text {eq }}$ for the iceberg detections in (a) falling within 2-week periods. The shaded region in both panels indicates the period when the G1 site was covered by land-fast ice (see section 4c).

defined the reflection curve, or for cases where there was no clear $\tau_{\min }$ because of the lockout time (e.g., 5 February 2012), because of a complicated keel shape (e.g., 4 January 2012) or because multiple icebergs were in the field of view at one time (e.g., 4 April 2012). A histogram of the speeds for the 178 cases where speed could be determined is plotted in Fig. 12c.

Except for the period of land-fast sea ice cover, the 285 iceberg detections (some of which represent more than one iceberg in the field of view at once) are uniformly distributed throughout the 8.5-month-long record (Fig. 13a). Furthermore, the likelihood of large icebergs (indicated by maximum $d_{\text {eq }}$ detected within 2-week intervals) is slightly higher in the first half of the record, though the "mean $d_{\mathrm{eq}}$ " (obtained by averaging $d_{\mathrm{eq}}$ for all of the icebergs within the 2-week intervals) shows no 


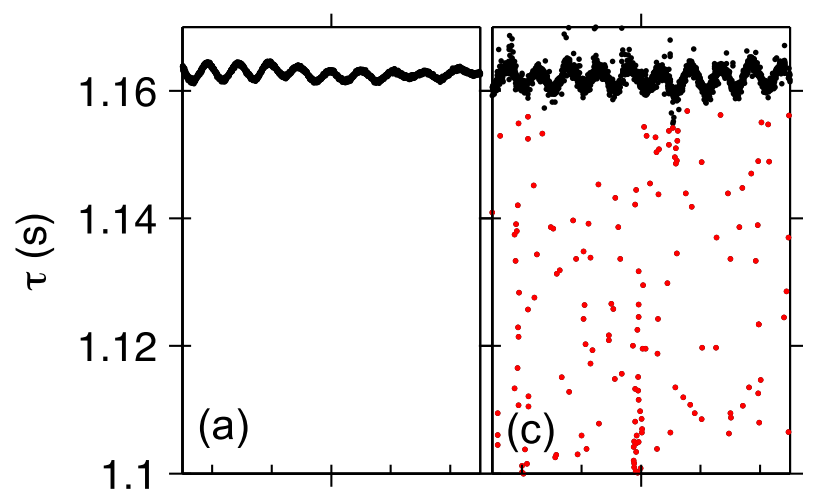

1 March 201225 July 2012

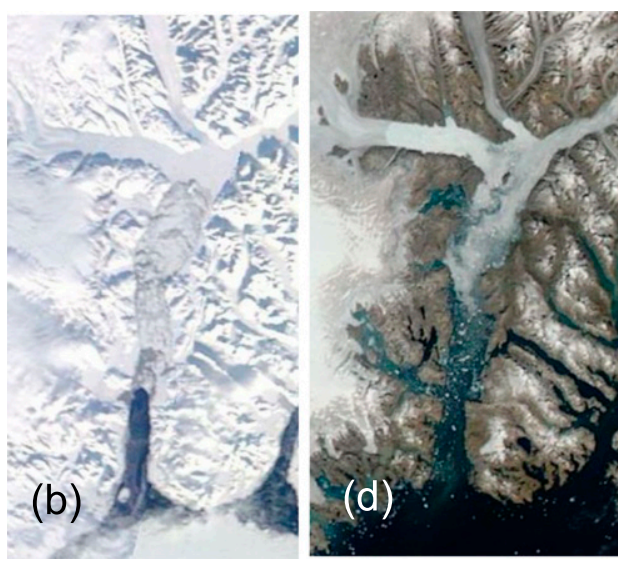

FIG. 14. Five-day segments of the $\tau$ time series (not detided) recorded during periods (a) with and (b) without land fast ice cover. Concurrent Terra satellite images of the fjord taken on (b) 1 Mar and (d) and 25 Jul. (c) Red dots highlight subsurface echoes (i.e., $\tau$ reflections from surfaces within the water column). Note that difference in the amplitude of the tidal contribution to $\tau$ in (a) and (c) is due to the spring-neap cycle, not the presence of sea ice: 1 Mar 2012 fell during a neap tide, while $25 \mathrm{Jul} 2012$ was about halfway between the spring and the neap tides.

discernable trend during the record (Fig. 13b). Details of the dynamics controlling iceberg drift speed and comparisons between the drift speeds with contemporaneous ADCP-derived velocity profiles and winds from Sermilik Fjord will be discussed elsewhere (A. Silvano et al. 2015, unpublished manuscript).

\section{2) LAND-FAST SEA ICE IN THE SERMILIK FJORD}

Finally, there is a striking 2-week period (26 February 2012-10 March 2012) when there is only one early echo (Fig. 10b with a 5-day close-up shown in Fig. 14). During this period, the individual $\tau$ measurements within each burst are remarkably uniform: the average of the standard deviations of $\tau$ in each four-ping burst is less than half that for the record taken as a whole ( 0.22 vs $0.54 \mathrm{~ms}$ ). As discussed in section $3 \mathrm{a}$, during this time land-fast ice likely suppressed surface variability in $\tau$ (by suppressing surface gravity waves) and also prevented icebergs from passing by the IES, thereby eliminating that source of early echoes. This interpretation is consistent with Terra satellite imagery (Fig. 14b), which shows the area from Helheim Glacier to mid-fjord (where G1 was situated) locked in a cover of ice. For comparison, an ice-free period is shown in the travel-time record with its concurrent satellite image (Figs. 14c,d).

\section{Conclusions}

While there has been increased attention dedicated to understanding processes operating in high-latitude seas, shelves, and fjords, these regions present logistic challenges for making observations. Though in situ data are required for model assessments and to ground truth or calibrate remotely sensed data, these regions remain largely undersampled and sustained in situ measurements to investigate interannual variability are particularly lacking. The use of PIESs to characterize variability at high latitudes as described here is a novel application of an existing technology and PIESs present a promising and cost-effective way to improve understanding of fjord dynamics and shelf-fjord interactions and will increase long-term monitoring capabilities in high latitudes, where remoteness and harsh conditions hamper traditional in situ observation techniques.

Results from the 1-yr test deployment in Sermilik Ford have demonstrated that in order to use PIESs in high latitudes to measure acoustic reflections from the sea surface, one must carefully identify and filter the signal due to sea ice reflections. Furthermore, the methodologies developed here for measuring iceberg speed and constraining iceberg draft provide submarine information about these icebergs, which is presently lacking. The methods do have significant limitations: (i) iceberg speed rather than velocity is determined; (ii) the detection area depends on $D$ and is also smaller for those shallow $\left(d<d_{\text {lim }}\right)$ icebergs with smaller draft (Fig. 3b, red circle); and (iii) iceberg draft range, rather than absolute draft, is determined. However, it is anticipated that applications with multiple PIESs or with PIESs in conjunction with land-based time lapse cameras may provide further information that can be used to constrain iceberg-ocean interactions and ultimately the link between ice sheets, ocean, and climate. Studies pursuing such applications are ongoing.

Acknowledgments. This work was supported by the National Science Foundation through the Divisions of Ocean Science and Polar Programs under Grant PLR1332911. A. Silvano was supported as a WHOI guest student through a Gori Fellowship. We are grateful to 
Erran Sousa (University of Rhode Island) for his tremendous assistance and advice and for preparing the PIES for this "high risk" deployment and to David Sutherland (University of Oregon) for successfully deploying and recovering the PIES. We are also grateful to Maureen Kennelly and Karen Tracey (University of Rhode Island) for their assistance with logistics and with data interpretation. We acknowledge the helpful comments provided by Derek Mueller (Carleton University) and two anonymous reviewers.

\section{REFERENCES}

Andres, M., F. Straneo, and D. Sutherland, 2014: Heat and ice in Sermilik Fjord: Novel observational techniques using PIES. 2014 Fall Meeting, San Francisco, CA, Amer. Geophys. Union, Abstract C23C-0422.

Andresen, C. S., and Coauthors, 2011: Rapid response of Helheim Glacier in Greenland to climate variability over the past century. Nat. Geosci., 5, 37-41, doi:10.1038/ngeo1349.

Bamber, J. L., R. L. Layberry, and S. P. Gogineni, 2001: A new ice thickness and bedrock data set for the Greenland ice sheet: Measurement, data reduction, and errors. J. Geophys. Res., 106, 33 773-33 780, doi:10.1029/2001JD900054.

Barker, A., M. Sayed, and T. Carrieres, 2004: Determination of iceberg draft, mass and cross-sectional areas. The Proceedings of the 14th International Offshore and Polar Engineering Conference, J. S. Chung et al., Eds., Vol. 1, ISOPE, 899-904.

Behrendt, A., E. Fahrbach, M. Hoppema, G. Rohardt, O. Boebel, O. Klatt, A. Wisotzki, and H. Witte, 2011: Variations of Winter Water properties and sea ice along the Greenwich meridian on decadal time scales. Deep-Sea Res. II, 58, 2524 2532, doi:10.1016/j.dsr2.2011.07.001.

Bigg, G. R., M. R. Wadley, D. P. Stevens, and J. A. Johnson, 1996: Prediction of iceberg trajectories for the North Atlantic and Arctic oceans. Geophys. Res. Lett., 23, 3587-3590, doi:10.1029/ 96GL03369.

Boldt, K. V., C. A. Nittrouer, B. Hallet, M. N. Koppes, B. K. Forrest, J. S. Wellner, and J. B. Anderson, 2013: Modern rates of glacial sediment accumulation along a $15^{\circ} \mathrm{S}-\mathrm{N}$ transect in fjords from the Antarctic Peninsula to southern Chile. J. Geophys. Res. Earth Surf., 118, 2072-2088, doi:10.1002/jgrf.20145.

Del Grosso, V. A., 1974: New equation for the speed of sound in natural waters (with comparisons to other equations). J. Acoust. Soc. Amer., 56, 1084-1091, doi:10.1121/1.1903388.

Donohue, K. A., D. R. Watts, K. L. Tracey, A. D. Greene, and M. Kennelly, 2010: Mapping circulation in the Kuroshio Extension with an array of current and pressure recording inverted echo sounders. J. Atmos. Oceanic Technol., 27, 507527, doi:10.1175/2009JTECHO686.1.

Enderlin, E. M., and G. S. Hamilton, 2014: Estimates of iceberg submarine melting from high-resolution digital elevation models: Applications to Sermilik Fjord, East Greenland. J. Glaciol., 60, doi:10.3189/2014JoG14J085.

—, I. M. Howat, S. Jeong, M.-J. Noh, J. H. van Angelen, and M. R. van den Broeke, 2014: An improved mass budget for the Greenland ice sheet. Geophys. Res. Lett., 41, 866-872, doi:10.1002/2013GL059010.

Fequest, D., 2005: MANICE: Manual of Standard Procedures for Observing and Reporting Ice Conditions. 9th ed. Environment Canada, $130 \mathrm{pp}$.
Harden, B. E., R. S. Pickart, and I. A. Renfrew, 2014: Offshore transport of dense water from the East Greenland shelf. J. Phys. Oceanogr., 44, 229-245, doi:10.1175/ JPO-D-12-0218.1.

Jackson, R. H., 2014: A mooring in Iceberg Alley: Fjords may link warming oceans and melting glaciers. Oceanus Magazine, 25 July. [Available online at http://www.whoi.edu/oceanus/ feature/a-mooring-in-iceberg-alley.]

—, F. Straneo, and D. A. Sutherland, 2014: Externally forced fluctuations in ocean temperature at Greenland glaciers in non-summer months. Nat. Geosci., 7, 503-508, doi:10.1038/ ngeo2186.

Kennelly, M. A., K. L. Tracey, and D. R. Watts, 2007: Inverted echo sounder data processing manual. University of Rhode Island GSO Tech. Rep. 2007-02, 89 pp. [Available online at http://www.po.gso.uri.edu/dynamics/publications/tech_rpts/ IESprocessman.pdf.]

Kubat, I., M. Sayed, S. B. Savage, and T. Carrieres, 2005: An operational model of iceberg drift. The Proceedings of the 15th International Offshore and Polar Engineering Conference, J. S. Chung et al., Eds., Vol. 1, ISOPE, 752-758.

,,,--- , and G. Crocker, 2007: An operational iceberg deterioration model. The Proceedings of the 17th International Offshore and Polar Engineering Conference, J. S. Chung et al., Eds., Vol. 1, ISOPE, 652-657.

Li, Q., D. M. Farmer, T. F. Duda, and S. Ramp, 2009: Acoustical measurement of nonlinear internal waves using the inverted echo sounder. J. Atmos. Oceanic Technol., 26, 2228-2242, doi:10.1175/2009JTECHO652.1.

Meinen, C. S., and D. R. Watts, 2000: Vertical structure and transport on a transect across the North Atlantic Current near $42^{\circ} \mathrm{N}$ : Time series and mean. J. Geophys. Res., 105, 21869 21 892, doi:10.1029/2000JC900097.

Melling, H., 1998: Sound scattering from sea ice: Aspects relevant to ice-draft profiling by sonar. J. Atmos. Oceanic Technol., 15, 1023-1034, doi:10.1175/1520-0426(1998)015<1023: SSFSIA $>2.0 . \mathrm{CO} ; 2$

Pickart, R. S., F. Straneo, and G. W. K. Moore, 2003: Is Labrador Sea Water formed in the Irminger Sea? Deep-Sea Res. I, 50, 23-52, doi:10.1016/S0967-0637(02)00134-6.

Rignot, E., I. Velicogna, M. R. van den Broeke, A. Monaghan, and J. T. M. Lenaerts, 2011: Acceleration of the contribution of the Greenland and Antarctic ice sheets to sea level rise. Geophys. Res. Lett., 38, L05503, doi:10.1029/2011GL046583.

Rossby, T., 1969: On monitoring depth variations of the main thermocline acoustically. J. Geophys. Res., 74, 5542-5546, doi:10.1029/JC074i023p05542.

Stouffer, R. J., and Coauthors, 2006: Investigating the causes of the response of the thermohaline circulation to past and future climate changes. J. Climate, 19, 1365-1387, doi:10.1175/ JCLI3689.1.

Straneo, F., G. S. Hamilton, D. A. Sutherland, L. A. Stearns, F. Davidson, M. O. Hammill, G. B. Stenson, and A. RosingAsvid, 2010: Rapid circulation of warm subtropical waters in a major glacial fjord in East Greenland. Nat. Geosci., 3, 182-186, doi:10.1038/ngeo764.

—, R. G. Curry, D. A. Sutherland, G. S. Hamilton, C. Cenedese, K. Väge, and L. A. Stearns, 2011: Impact of fjord dynamics and subglacial discharge on the circulation near Helheim Glacier. Nat. Geosci., 4, 332-327, doi:1038.ngeo1109.

, and Coauthors, 2012: Characteristics of ocean waters reaching Greenland's glaciers. Ann. Glaciol., 53, doi:10.3189/ 2012AoG60A059. 
- and Coauthors, 2013: Challenges to understanding the dynamic response of Greenland's marine terminating glaciers to oceanic and atmospheric forcing. Bull. Amer. Meteor. Soc., 94, 1131-1144, doi:10.1175/BAMS-D-12-00100.1.

Sutherland, D. A., and R. S. Pickart, 2008: The East Greenland Coastal Current: Structure, variability, and forcing. Prog. Oceanogr., 78, 58-77, doi:10.1016/ j.pocean.2007.09.006.

_, F. Straneo, G. B. Stenson, F. J. M. Davidson, M. O. Hammill, and A. Rosing-Asvid, 2013: Atlantic water variability on the
SE Greenland shelf and its relationship to SST and bathymetry. J. Geophys. Res. Oceans, 118, 847-855, doi:10.1029/ 2012JC008354.

, G. E. Roth, G. S. Hamilton, S. H. Mernild, L. A. Stearns, and F. Straneo, 2014: Quantifying flow regimes in a Greenland glacial fjord using iceberg drifters. Geophys. Res. Lett., 41, 8411-8420, doi:10.1002/2014GL062256.

Watts, D. R., and Coauthors, 2006: Currents, eddies, and a "fish story" in the southwestern Japan/East Sea. Oceanography, 19, 64-75, doi:10.5670/oceanog.2006.44. 